values. It includes replacement cost for 1,650 hospital beds and for seriously damaged or destroyed public buildings. Damage to industry, including handicraft and small industry is estimated at $\$ 599$ million. Damage to agriculture amounted to $\$ 479$ million which has now risen to $\$ 610$ million.

Damage to public works and utilities amounted to $\$ 240$ million including repair costs for the water supply, sewers, electrical facilities, aqueducts, road and railway communications. Loss of revenue from commerce is estimated at $\$ 240$ million, and $\$ 176$ million will be required for the ropair and extension of the flood control of the Tagliamento valley. There is $\$ 49$ million-worth of damage to school buildings and a sum of $\$ 96$ million has been allocated for the repair of the few historical monuments that survived the shock. About 600 churches were destroyed or damaged beyond repair and damage to historical buildings, castles and works of art cannot be calculated.

One of the conclusions that can be drawn from the study of the Gemona earthquake is that this event could easily have been expected from what we know about the seismicity of the region. This earthquake demonstrated once more the economic vulnerability of developed and densely populated regions of apparently low seismicity to strong carthquakes of long return period but short recurrence interval. It also demonstrated the need for the application in such regions of minimum earthquake resistant design requirements in the construction of new buildings and for the strengthening of old ones, particularly of historical monuments and art treasures. The amount and extent of damage caused by the earthquake and by its aftershocks have important implications for the insurance industry and for the social and economic planning in earthquake areas.

The field work reported in this study constitutes par of the work carried out on a UNESCO Earthquak Reconnaissance Mission to Friuli (Ambraseys N. The Gemona di Friuli (ltaly) earthquake of May $1976^{\circ}$ UNESO Rec. Mission Report. No i 27.3.182 (1976). Uness Comelli, the Directur of Forestry Regione. Bott. A Comelli, the Director of Forestry. Dott. R. Querin operation.

\title{
Prediction: the negative aspects
}

The ability to predict earthquakes should reduce deaths, injuries, and property damage, but the prediction itself can have some negative effects. Henry Lansford sent this report from Boulder, Colorado, on a new study of the socioeconomic impacts of earthquake prediction:

WHEN social scientists go out into the real world to study a subject that has attracted a good deal of public attention, they usually come up with two classes of conclusions. The first class includes unsurprising findings that often provoke sceptics to snort that social science research is a waste of time-" common sense would have told you that!" But in addition to confirming some things that common scrise might suggest, good social science research can turn up some surprises too-the unexpected insights into human behaviour that the sociologists like to call "counterintuitive conclusions."

An 18-month study* of the potential impacts of earthquake prediction in the United States, conducted at the University of Colorado with support from the National Science Foundation, has produced both kinds of conclusions. The research team concluded, for example, that although the first credible predictions of damaging earthquakes months or years before they occur can save many lives and reduce property losses, such predictions can also result in severe economic depression and social disruption in the communities for which earthquakes are predicted. Although nobody had given much thought to this negative aspect of earthquake prediction, it should not come as a great surprise that property values and tax revenues will decline in an area for which an earthquake is predicted; that business activity, employment opportunities, and public services will be reduced; and that the sale of earthquake insurance policies will cease as soon as the prediction is issued.

But there are also some counterintuitive conclusions. The researchers found few indications that homeowners who have small equities in heavily mortgaged homes would simply walk away and stop making their monthly payments, contrary to what common sense with a touch of cynicism might suggest. They found that savings deposits in banks in the "target community" for which the earthquake is predicted would go up instead of down with the rest of the economy, as people save money instead of spending it on household appliances or other property that might be damaged or destroyed by the earthquake. And, perhaps most surprising of all, they found that $40 \%$ of the residents would remain, rather than evacuating either temporarily or permanently, in an area for which an earthquake five times as great as the one that devastated San Fernando, California, in 1971 has been predicted, even if they believe that the prediction is accurate.

The research team, which included both physical and social scientists, did most of their field work in California, which has had more recent experience with earthquakes, as well as more trepidation about future ones, than any other part of the United States. The team also looked closely at earthquake-prediction research that has been going on in China, Japan, and the Soviet Union. They began by getting estimates from seismologists of the probable characteristics of the first official, scientifically-based carthquake prediction in the United States and of the way in which it would probably be released to the public. Then they formulated two "prototype" predictions: onc assumed a five-month lead time, a $50 \%$ probability of occurrence, and an earthquake with a magnitude of 6.3 on the Richter scale: the second assumed a three-year lcad time and a 7.3 magnitude. Then they conducted more than 1,000 intervicws throughout California, with federal, state, and local government officials, executives of large and small businesses, managers of large and small news media and individual families.

Three of the study's findings are regarded as particularly significant:

- Under existing laws, it is not clear whether federal disaster-relief funds can be committed on the basis of an official earthquake prediction or whether it will be necessary to wait until earthquake damage has occurred hefore committing funds that might have helped prevent the damage.

- No workable alternative to earthquake insurance exists for indemnifying those whose property is damaged or destroyed by an earthquake, although the California state insurance commissioner has stated that he will stop the sale of new earthquake insurance policies in any area for which a credible official earthquake prediction has been issued.

- Damage estimate maps, hased on solid scientific data and published by news media in the threatened area, should reduce property damage considerably if the earthquake prediction provides enough lead time to reinforce structures and undertake other damage-prevention measures. $\square$

* J. Eugene Haas and Dennis S. Mileti. Socioecunomic Impact of Earthquake Prediction (Institute of Behavinural Science. University of Colorado, Boulder, Colorado; 1976) 